\title{
Medium-Term Clinical Outcomes of Deep Anterior Lamellar Keratoplasty versus Penetrating Keratoplasty for Macular Corneal Dystrophy
}

\author{
Ahmad AlAraj ${ }^{1,2}$ \\ Ahmad AlAmeer ${ }^{1,3}$ \\ Samar Al-Swailem (ID) \\ 'Anterior Segment Division, Department \\ of Ophthalmology, King Khaled Eye \\ Specialist Hospital, Riyadh, Kingdom of \\ Saudi Arabia; ${ }^{2}$ Department of \\ Ophthalmology, College of Medicine, \\ Qassim University, Qassim, Saudi Arabia; \\ ${ }^{3}$ Ophthalmology Division, Surgery \\ Department, King Abdullah bin Abdulaziz \\ University Hospital, Riyadh, Saudi Arabia
}

Purpose: To compare the postoperative outcomes of deep anterior lamellar keratoplasty (DALK) and penetrating keratoplasty (PKP) for macular corneal dystrophy (MCD).

Design: Single-center, retrospective, interventional case series.

Methods: A chart review was performed of 100 patients (157 eyes) who underwent primary DALK (DALK group) and PKP (PKP group) for histopathologically confirmed MCD for whom at least 12 months of follow-up were available. Between-group comparisons were performed of visual acuity (VA), graft survival, and postoperative complications.

Results: There were 22 eyes in the DALK group and 135 in the PKP group. Postoperative best-corrected visual acuity (BCVA) of $20 / 40$ or better was achieved in $90.9 \%$ of the DALK group and $76.3 \%$ of the PKP group $(P=0.12)$. At last visit, graft survival was $95.5 \%$ (21 eyes) and $91.1 \%$ (123 eyes) in DALK and PKP groups, respectively ( $P=0.69$, Log rank test). Corneal graft rejection episodes occurred in 1 (4.5\%) DALK graft and 19 (14.1\%) PKP grafts. Five of the 19 graft rejections in the PKP group were irreversible. Microbial keratitis and cataract occurred in $6(4.5 \%)$ and $15(11.1 \%)$ PKP eyes. One (4.5\%) eye in the DALK group had cataract and none of the DALK cases developed microbial keratitis. Clinically significant recurrence was observed in 4 (2.9\%) PKP eyes and 1 (4.5\%) DALK eye $(P=0.69)$, respectively.

Conclusion: DALK is a viable option for MCD without Descemet membrane involvement. DALK had comparable medium-term visual and survival outcomes to PKP. DALK has the advantage of lower open sky intraoperative complications and lower graft rejection episodes. Keywords: macular corneal dystrophy, keratoplasty, lamellar keratoplasty, penetrating keratoplasty

\section{Plain Language Summary}

There are a few studies comparing short-term outcomes of penetrating keratoplasty (PKP) and deep anterior lamellar keratoplasty (DALK) in macular corneal dystrophy (MCD) cases. One study concluded that DALK is associated with visually significant recurrence. Another two comparative studies reported comparable visual outcomes and superior safety of DALK. The current study presents the medium-term outcomes of DALK in comparison to PKP for MCD. To our knowledge, this is the largest series of patients reported to date, which had addressed many comparative variables, including: visual outcome, graft survival, complication and recurrence of disease. Comparison of DALK and PKP in this study indicates DALK is a viable option for MCD without Descemet membrane involvement and carries advantages such as lower graft rejection. 


\section{Introduction}

Macular corneal dystrophy (MCD) is a bilateral progressive autosomal recessive disorder clinically characterized by stromal opacities with indistinct borders. ${ }^{1,2}$ Although MCD is less common than other types of stromal dystrophies worldwide, it is the most common corneal dystrophy in Saudi Arabia due to higher consanguinity in the region. ${ }^{3,4} \mathrm{MCD}$ is also the most prevalent stromal dystrophy in India, Iceland and some regions of the USA. ${ }^{5}$

Histopathologically, MCD is characterized by accumulation of glycosaminoglycans under the epithelium, between stromal lamellae, within the keratocytes and endothelial cells, which stains positive with alcian blue, colloidal iron, metachromatic dyes and periodic acid-Schiff. ${ }^{1,6}$ Three variants of MCD (Type 1, 1A and 2) are distinguished based on immunoreactivity of antigenic keratan sulfates in the cornea and the serum. ${ }^{3,6-9}$ The most common subtypes of MCD in Saudi Arabia are Type 1 and $1 \mathrm{~A}$, which require earlier surgical intervention than type $2 ., 8,10$

Traditionally, penetrating keratoplasty (PKP) has been performed to restore visual acuity with excellent result in MCD. ${ }^{1,10}$ However, due to the risk of endothelial rejection and intraocular complications, several anterior lamellar keratoplasty techniques have been described such as deep anterior lamellar keratoplasty (DALK). "Big bubble" DALK is a popular technique proposed initially by Dr Anwar in 1974 and described in details in 2002 by Anwar and Teichmann in Saudi Arabia. This technique involves partial-thickness trephination followed by injection of air into the corneal stroma to create a large bubble between DM and corneal stroma. ${ }^{11}$ DALK is considered an alternative to PKP in MCD without Descemet's membrane or endothelium involvement. ${ }^{12,13}$ Although DALK offers several advantages over PKP, some investigators believe that DALK is not a good option for MCD due to the higher rate of interface opacity and endothelial cell loss. ${ }^{14,15}$ A retrospective comparative study reported that DALK was associated with greater recurrence of MCD and lower visual acuity than PKP. ${ }^{16}$ However, two other comparative studies reported comparable visual outcomes and superior safety of DALK. ${ }^{17,18}$ The aim of this study is to compare the postoperative outcomes of DALK and PKP in a large series of MCD patients.

\section{Methods}

The study (RP 1460-R) was approved by Institutional Review Board (IRB)/Ethics Committee at the King
Khaled Eye Specialist Hospital (KKESH), Riyadh, Saudi Arabia. Moreover, the tenets of the Declaration of Helsinki were followed at each step of the study. This study evaluated patients who had undergone DALK and PKP at KKESH Hospital between January 1, 1997 and December 31, 2013. Patients were included in the study if they were diagnosed with MCD with histopathologic confirmation and a minimum of 12 months postoperative follow-up. Consent to review their medical records was not required by the IRB, and all data was coded to ensure privacy and confidentiality of patients.

All surgeries were performed by members of Anterior Segment Division at King Khaled Eye Specialist Hospital. Sizing of the host trephine depended on several factors, including host corneal size, recurrence, and risk of rejection. The donor tissue trephine was routinely sized $0.5 \mathrm{~mm}$ larger than the host trephine. For patients with a largerthan-average corneal horizontal diameter (limbal white-towhite measurement $\geq 12.5 \mathrm{~mm}$ ) an 8.0 or $8.25 \mathrm{~mm}$ host trephine was used, and for patients with a smaller thanaverage corneal diameter (white-to-white measurement $\leq 11.5 \mathrm{~mm}$ ), a 7.0 or $7.25 \mathrm{~mm}$ trephine was used. A number of different methods were used for DALK, but 3 dissection techniques were used to facilitate removal of host tissue down to Descemet membrane including viscoelastic, hydration, or the "big bubble" technique. The surgical technique varied based on the extent of corneal pathology and personal experience. The postoperative regimen included a combination of topical antibiotic and steroid. Topical Ofloxacin 0.3\% (Optiflox, Jamjoom) or moxifloxacin $0.5 \%$ QID (vigamox, Alcon) were prescribed for 2-3 weeks. Topical prednisolone acetate 1\% (Pred Forte, Allergan) were used for at least the first 6-9 months in PKP eyes and for at least 6 months for eyes that underwent DALK. Postoperatively, most patients were evaluated at 1 day, 1 week, 1 month and every 3 months for 2 years and yearly thereafter. Suture removal varied among different surgeons. Some removed all the sutures at 12 to 36 months while others selectively removed either loose or tight sutures to correct astigmatism.

A chart review was performed to collect data on patients' demographics, preoperative uncorrected visual acuity (UCVA) and best corrected visual acuity (BCVA), intraoperative and postoperative complications, and subsequent surgical procedures. Postoperative graft clarity, UCVA and BCVA were recorded in the last follow-up visit. Graft failure was defined as irreversible loss of central graft clarity, irrespective of the level of the VA. 
Clinically significant recurrence was defined as biomicroscopic evidence of recurrent disease and deterioration of BCVA to $20 / 40$ or worse.

Statistical analysis was performed with Statistical Package for Social Sciences (SPSS 25; IBM Corp., Armonk, NY, USA). In patient who underwent bilateral surgery, each eye was analyzed separately. Demographic variables were summarized as frequency (percentage), mean \pm standard deviation, or median (interquartile range) according to the type and distribution of variables. The proportions of all categorical variables (gender, type of surgery, causes of graft failure, graft survival) were analyzed. Categorical variables were compared with the Chi squared test and the Mann Whitney $U$-test was used to compare continuous variables. Log rank test was utilized for survival comparison. A P value less than 0.05 was considered statistically significant. Graft survival curves were produced using the standard Kaplan-Meier method.

\section{Result}

The study sample was comprised of 157 eyes of 100 patients with histopathologically proven MCD. DALK was performed in 22 eyes (18 patients; DALK group) and 135 eyes (82 patients; PKP group) underwent PKP. The mean postoperative follow-up was $7.2 \pm 6.20$ years for the DALK group and after PKP was $9.7 \pm 4.1$ years. Table 1 presents the characteristics of patients in both groups.

\section{Visual Outcomes}

Table 2 presents the postoperative visual outcomes after DALK and PKP. At last follow up, the BCVA was not significantly different between groups $(P=0.4)$. BCVA of $20 / 40$ or better was achieved in $20(90.9 \%)$ eyes in the

Table I Characteristics of Macular Corneal Dystrophy Patients Who Underwent Deep Anterior Lamellar Keratoplasty and Penetrating Keratoplasty

\begin{tabular}{|l|c|c|c|}
\hline Parameters & $\begin{array}{c}\text { DALK } \\
(\mathbf{n = 2 2})\end{array}$ & $\begin{array}{c}\text { PKP } \\
(\mathbf{n = 1 3 5 )}\end{array}$ & P-value \\
\hline Sex, Female: Male & $12: 6$ & $43: 39$ & 0.27 \\
Laterality, OD: OS: OU & $9: 5: 4$ & $1 \mathrm{I}: 18: 53$ & $<0.00 \mathrm{I}$ \\
Mean age at surgery \pm SD & $28.2 \pm 7.5$ & $31.5 \pm 8.4$ & 0.76 \\
years & & & \\
Mean follow-up \pm SD years & $7.2 \pm 6.2$ & $9.7 \pm 4.1$ & 0.08 \\
Mean donor size \pm SD & $7.8 \pm 0.28$ & $7.7 \pm 0.26$ & 0.05 \\
Mean recipient size \pm SD & $7.5 \pm 0.35$ & $7.3 \pm 0.31$ & 0.1 \\
\hline
\end{tabular}

Abbreviations: DALK, deep anterior lamellar keratoplasty, PKP, penetrating keratoplasty; OD, right eye; OS, left eye; OU, both eyes; BCVA, best corrected visual acuity; UCVA, uncorrected visual acuity; SD, standard deviation.
Table 2 Visual Outcome (LogMAR) After Deep Anterior Lamellar Keratoplasty and Penetrating Keratoplasty for Macular Corneal Dystrophy

\begin{tabular}{|l|c|c|c|}
\hline Parameters & $\begin{array}{c}\text { DALK } \\
(\mathbf{n}=\mathbf{2 2})\end{array}$ & $\begin{array}{c}\text { PKP } \\
\mathbf{( n = 1 3 5 )}\end{array}$ & P value \\
\hline Pre-operative mean UCVA \pm SD & $0.88 \pm 0.2$ & $0.82 \pm 0.3$ & 0.25 \\
Pre-operative mean BCVA \pm SD & $0.78 \pm 0.25$ & $0.75 \pm 0.29$ & 0.61 \\
Mean UCVA at last follow-up \pm SD & $0.43 \pm 0.21$ & $0.51 \pm 0.58$ & 0.23 \\
Mean BCVA at last follow-up \pm SD & $0.26 \pm 0.15$ & $0.28 \pm 0.27$ & 0.64 \\
Improvement in UCVA \pm SD & $0.45 \pm 0.35$ & $0.3 \pm 0.6$ & 0.1 \\
Improvement in BCVA \pm SD & $0.52 \pm 0.28$ & $0.47 \pm 0.32$ & 0.47 \\
\hline
\end{tabular}

Note: $P<0.05$ is statistically significant.

Abbreviations: DALK, deep anterior lamellar keratoplasty; PKP, penetrating keratoplasty; BCVA, best corrected visual acuity; UCVA, uncorrected visual acuity; SD, standard deviation.

DALK group and 103 (76.3\%) eyes in the PKP group $(P=$ 0.12 ). Figure 1 presents the preoperative BCVA and BCVA at last follow up in both groups.

\section{Graft Survival}

At the most recent visit, graft survival was $95.5 \%$ (21 eyes) and $91.1 \%$ (123 eyes) in the DALK and PKP groups, respectively ( $P=0.69$ by Log rank test). Figure 2 presents the graft survival probabilities for both groups. In PKP group, the main causes of graft failure were irreversible rejection in 5 eyes (41.6\%) and recurrence of MCD in 4 eyes (33.3\%). Graft failure secondary to endothelial decompensation was observed in 3 PKP eyes, 2 eyes after phacoemulsification and one after severe blunt trauma that resulted in graft dehiscence, glaucoma and aphakia. However, only 1 graft failed in DALK which was secondary to recurrence of MCD.

\section{Complications and Recurrence}

Intraoperatively, Descemet membrane microperforation occurred in 4 eyes (16\%) after DALK which was managed intraoperatively without visual sequelae. In PKP, the most common complications were rejection (14.1\%), cataract (10.7\%), and microbial keratitis (4.2\%) (Table 3). Clinically significant recurrence occurred in 1 eye $(4.5 \%)$ in the DALK group after 5.1 years. After PKP, recurrence occurred in 4 eyes (2.9\%) over a mean interval of $9.6 \pm 5.1$ years (range, 1.8 to 15.9 years). There was no statistically significant difference in recurrent episodes between groups $(P=0.69)$. A common risk factor of recurrence identified in both groups, which was a small recipient and donor size. In the PKP group, the size of the graft donor and recipient was $7.5 \mathrm{~mm}$ and $7.13 \mathrm{~mm}$ respectively. In the DALK group, the size of the graft donor and recipient was $7.50 \mathrm{~mm}$ and $7.0 \mathrm{~mm}$ respectively. 


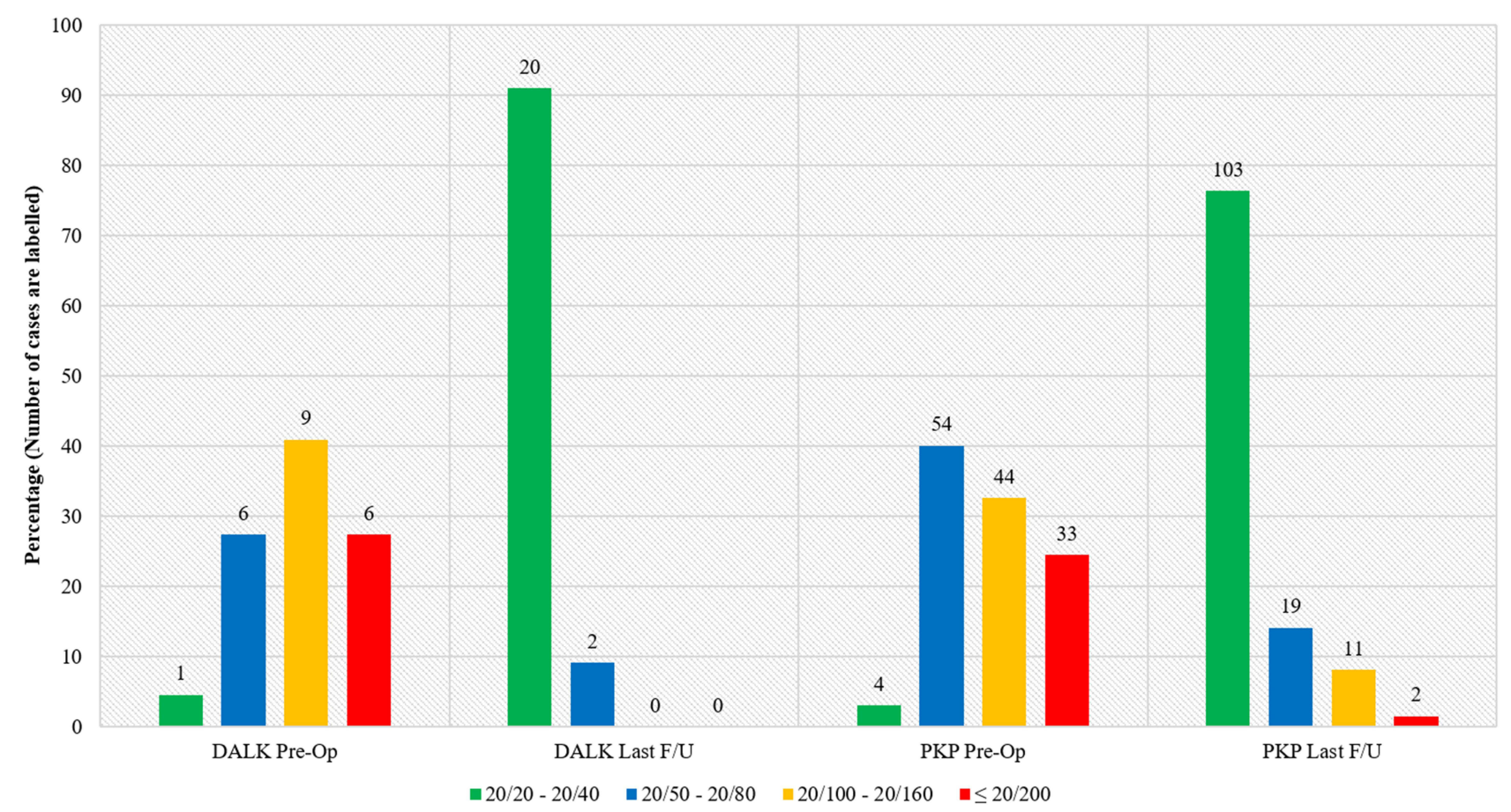

Figure I Best corrected visual acuity preoperative and at last follow-up of patient who underwent deep anterior lamellar keratoplasty and penetrating keratoplasty for macular corneal dystrophy.

Abbreviations: BCVA, best corrected visual acuity; DALK, deep anterior lamellar keratoplasty; PKP, penetrating keratoplasty; F/U, follow-up.

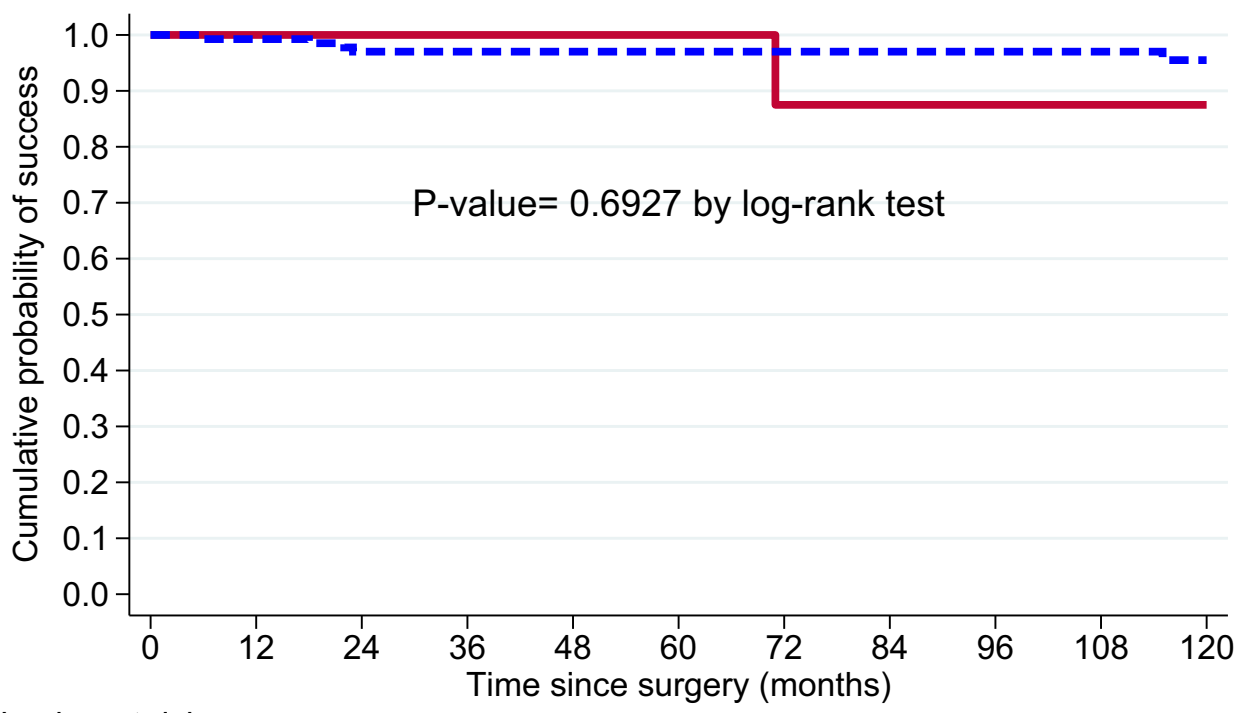

Number at risk

\begin{tabular}{|c|c|c|c|c|c|c|c|c|c|c|}
\hline $\begin{array}{l}\text { DALK } \\
\text { PKP }\end{array}$ & $\begin{array}{c}22 \\
135\end{array}$ & $\begin{array}{c}22 \\
134\end{array}$ & $\begin{array}{c}19 \\
129\end{array}$ & $\begin{array}{c}17 \\
127\end{array}$ & $\begin{array}{c}14 \\
123\end{array}$ & $\begin{array}{c}9 \\
114\end{array}$ & $\begin{array}{c}7 \\
111\end{array}$ & $\begin{array}{c}7 \\
98\end{array}$ & $\begin{array}{c}5 \\
86\end{array}$ & $\begin{array}{c}5 \\
76\end{array}$ \\
\hline & & & & & & & $=0$ & PKP & & \\
\hline
\end{tabular}

Figure 2 Graft survival curve and probabilities after deep anterior lamellar keratoplasty and penetrating keratoplasty for macular corneal dystrophy. Abbreviations: DALK, deep anterior lamellar keratoplasty; PKP, penetrating keratoplasty.

\section{Re-Grafting}

In the DALK group, no patient required regrafting. In the PKP group, regrafting was required in 6 eyes, 3 eyes due to irreversible rejection, 2 eyes secondary to endothelial decompensation after phacoemulsification, and one eye secondary to recurrence of MCD. However, in the other 
Table 3 Complications After Deep Anterior Lamellar Keratoplasty and Penetrating Keratoplasty for Macular Corneal Dystrophy

\begin{tabular}{|l|c|c|}
\hline Complication & DALK (22) & PKP (135) \\
\hline Intra-operative microperforation & 4 & 0 \\
Descemet's membrane detachment & 0 & 0 \\
Graft Rejection & 1 & 19 \\
Microbial keratitis & 0 & 6 \\
Traumatic wound dehiscence & 0 & 3 \\
Glaucoma & 0 & 1 \\
Cataract & 1 & 15 \\
Fixed dilated pupil & 0 & 2 \\
Rhegmatogenous retinal detachment & 0 & 2 \\
\hline
\end{tabular}

Abbreviations: DALK, deep anterior lamellar keratoplasty; PKP, penetrating keratoplasty; MCD, Macular stromal dystrophy.

failed cases, the patients preferred to wait until VA was significantly impaired.

\section{Discussion}

This comparative case series presents the visual outcome, graft survival, complication and recurrence of disease in eyes undergoing DALK or PKP for MCD. Successful outcomes of PKP for MCD have been previously reported. However, few studies have reported the outcomes of DALK in comparison to PKP for MCD. ${ }^{14,16-18}$ The current study presents the medium-term outcomes of DALK in comparison to PKP for MCD. To our knowledge, this is the largest series of patients reported to date, which had addressed many comparative variables, including: visual outcome, graft survival, complication and recurrence of disease.

Unequal distribution of cases between both groups related to many factors including: surgeon experience, surgeon preference and extent of central corneal thinning. In early 1990s, most of corneal surgeons in our institute noticed more recurrence of the disease in eyes that underwent anterior lamellar keratoplasty; therefore, many were conservative in performing DALK for eyes with same pathology. In addition, it is technically more difficult and time consuming to do DALK than PKP for eyes with MCD.

In the current study, there was no statistically significant difference in the postoperative visual outcomes between DALK and PKP. Postoperatively, UCVA and BCVA improved significantly in both groups. This concur with the previously published studies. ${ }^{14,15,17-20}$ In our series, $90.9 \%$ of eyes in the DALK group and $76.3 \%$ of eyes in the PKP group achieved 20/40 or better vision. These outcomes are better than those reported by Reddy et al and Sari et al ${ }^{17,18}(67-70.7 \%)$ for DALK and for PKP (60-68.5\%). Improved surgical techniques for DALK and advances in refractive surgery after keratoplasty may explain the difference between the current study and previous studies. ${ }^{17,18}$

Excellent long-term graft survival in corneal dystrophies has been linked to the avascular nature of these disorders, minimal ocular surface disease, and operating on a young, compliant patient who has easy access to healthcare facilities. ${ }^{10,21,22}$ In the current study, at the most recent follow up visit, $95.5 \%$ of DALK cases were clear which is slightly higher than previously published studies (80-85.7\%). ${ }^{14,16,17}$ In the PKP group, $91.1 \%$ of the grafts were clear in our series which is comparable to the graft survival (77-90\%) reported in three large series of PKP for MCD. ${ }^{10,16,17}$

DALK is a more technically challenging procedure with a steep learning curve and carries a high risk of intraoperative complication such as double anterior chamber which can be a major cause for failure ${ }^{14,17}$ However, DALK does not violate the intraocular structures of the eye, reducing the chance of postoperative glaucoma, cataract formation, retinal detachment, cystoid macular edema, expulsive choroidal hemorrhage and epithelial ingrowth. Intraoperative complications vary depending on surgeon experience. In the current study, corneal surgeons have been performing DALK since 2002. In our series, four cases had Descemet membrane perforation which was managed successfully intraoperatively without subsequent double anterior chamber. Although PKP is technically easier, it increases the risk of postoperative complications such as cataract and increases intraocular pressure due to disturbed intraocular structures and prolonged use of steroid. ${ }^{14}$ Additionally, endothelial rejection is a major complication after PKP which occurs in $12-24 \%$ of all cases. $^{10,16-18}$ In our series, graft rejection episodes occurred in $14 \%$ of PKP group and of which $26.3 \%$ were irreversible. Stromal rejection occurred in only 1 eye $(4.5 \%)$ in the DALK group and responded well to medical treatment. In their comparative study, Sari et $\mathrm{al}^{18}$ reported a higher percentage $(8.5 \%)$ of stromal rejection after DALK that were all successfully treated with topical steroids.

Recurrence of MCD in grafts requiring keratoplasty has been documented in literature. ${ }^{22-24}$ These cases appeared to be the result of the replacement of donor 
keratocytes by genetically defective host cells. ${ }^{24}$ As previously reported in a large retrospective series of PKP for $\mathrm{MCD}$, the incidence of recurrence correlated with the length of follow-up and inversely with the size of donor graft and recipient trephination. ${ }^{10}$ Akova et al reported recurrence times ranging from 20 months to 30 years. ${ }^{22}$ Perhaps the question of the more frequent recurrence rate on the graft in DALK vs PKP cannot yet be conclusively assessed here, based on a mean follow-up of $7.2 \pm 6.2$ years (DALK group) vs $9.7 \pm 4.1$ years (PKP group). In the current series, clinically significant recurrence of MCD occurred in $2.9 \%$ of the PKP group and $4.5 \%$ of the DALK group. The size of the graft donor and recipient were smaller than the total mean in both groups. Cheng et al reported that the recurrence risk after DALK is 5.066 higher than PKP. ${ }^{16}$ However, clinically significant recurrence of MCD after PKP ranged from $4.8 \%$ to $5.2 \%$ and $2.3 \%$ to $5.7 \%$ after DALK. ${ }^{10,12,18}$ These observations are comparable to our results. ${ }^{10,12,18}$

Descemet membrane and endothelial involvement has been histopathologically documented in patients with MCD. ${ }^{6,25}$ Kawashima et al ${ }^{14}$ reported progressive loss of endothelial density in patients with MCD who underwent DALK compared to PKP which might be attributed to the natural progression of the disease. However, several studies showed similar or lower endothelial cell loss in patients with MCD who underwent DALK in comparison to PKP. ${ }^{16,18,26}$ The retrospective nature of our study limits the availability of endothelial cell density measurements in all patients. Furthermore, the infrequent finding of MCD without Descemet membrane involvement limits the number of DALK cases in our series.

In conclusion, DALK is a viable alternative to PKP for managing MCD without Descemet membrane involvement. Our study demonstrated medium-term comparable visual and survival outcomes of DALK and PKP for MCD. DALK carries the advantage of better intraocular safety profile and lower graft rejection episodes. Further long-term studies are warranted on the endothelial cell density after DALK in MCD utilizing a larger sample size.

\section{Abbreviations}

DALK, deep anterior lamellar keratoplasty; PKP, penetrating keratoplasty; MCD, macular corneal dystrophy; VA, visual acuity; BCVA, best-corrected visual acuity; UCVA, uncorrected visual acuity; SPSS, Statistical Package for Social Sciences.

\section{Statement of Ethics}

The study (RP 1460-R) was approved by Institutional Review Board (IRB)/Ethics Committee at the King Khaled Eye Specialist Hospital (KKESH), Riyadh, Saudi Arabia. Moreover, the tenets of the Declaration of Helsinki were followed at each step of the study. Consent to review medical records of patients was not required by the IRB, and all data was coded to ensure privacy and confidentiality of patients.

IRB approved a waiver of consent process, after making the following determinations:

- The study involves no more than minimal risk to the subjects;

- The waiver or alteration will not adversely affect the rights and welfare of the subjects;

- The study could not practicably be carried out without the waiver.

\section{Funding}

There is no funding to report.

\section{Disclosure}

The authors declare that they have no conflicts of interest.

\section{References}

1. Aldave AJ, Vo RC, Sousa L, Mannis MJ. The stromal dystrophies. In: Mannis M, Holland E, editors. Cornea. 4th ed. Amsterdam: Elsevier; 2016:781-799.

2. Weiss JS, Møller HU, Aldave AJ, et al. IC3D classification of corneal dystrophies--edition 2. Cornea. 2015;34:117-159. doi:10.1097/ ICO.0000000000000307

3. Klintworth GK, Oshima E, al-Rajhi A, al-Saif A, Thonar EJ, Karcioglu ZA. Macular corneal dystrophy in Saudi Arabia: a study of 56 cases and recognition of a new immunophenotype. $A m$ J Ophthalmol. 1997;124:9-18. doi:10.1016/S0002-9394(14)71637-X

4. Al Faran MF, Tabbara KF. Corneal dystrophies among patients undergoing keratoplasty in Saudi Arabia. Cornea. 1991;10:13-16.

5. Klintworth GK. Corneal dystrophies. Orphanet J Rare Dis. 2009;4:7. doi:10.1186/1750-1172-4-7

6. Cursiefen C, Hofmann-Rummelt C, Schlötzer-Schrehardt U, et al. Immunohistochemical classification of primary and recurrent macular corneal dystrophy in Germany: subclassification of immunophenotype I A using a novel keratan sulfate antibody. Exp Eye Res. 2001;73:593-600. doi:10.1006/exer.2001.1080

7. Plaas AH, West LA, Thonar EJ, et al. Altered fine structures of corneal and skeletal keratan sulfate and chondroitin/dermatan sulfate in macular corneal dystrophy. J Biol Chem. 2001;276:39788-39796. doi:10.1074/jbc.M103227200

8. Klintworth GK, Meyer R, Dennis R, et al. Macular corneal dystrophy. Lack of keratan sulfate in serum and cornea. Ophthalmic Paediatr Genet. 1986;7:139-143. doi:10.3109/13816818609004130

9. Jonasson F, Oshima E, Thonar EJ, Smith CF, Johannsson JH, Klintworth GK. Macular corneal dystrophy in Iceland. A clinical, genealogic, and immunohistochemical study of 28 patients. Ophthalmology. 1996;103:1111-1117. doi:10.1016/S0161-6420(96) 30559-9 
10. Al-Swailem SA, Al-Rajhi AA, Wagoner MD. Penetrating keratoplasty for macular corneal dystrophy. Ophthalmology. 2005;11 2:220-224. doi:10.1016/j.ophtha.2004.08.017

11. Anwar M, Teichmann KD. Deep lamellar Keratoplasty: surgical techniques for anterior lamellar Keratoplasty with and without baring of Descemet's membrane. Cornea. 2002;21:374-383. 12. doi:10. 1097/00003226-200205000-00009

12. Unal M, Arslan OŞ, Atalay E, Mangan MS, Bilgin AB. Deep anterior lamellar keratoplasty for the treatment of stromal cornea dystrophies. Cornea. 2013;32(3):301-305. doi:10.1097/ICO.0b01 $3 \mathrm{e} 31825718 \mathrm{ca}$

13. Kodavoor SK, Deb B, Ramamurthy D. Deep anterior lamellar keratoplasty outcomes in macular and granular corneal dystrophy a comparative cross-sectional study. Indian $J$ Ophthalmol. 2019;67:1830-1833. doi:10.4103/ijo.IJO_1623_18

14. Kawashima M, Kawakita T, Den S, Shimmura S, Tsubota K, Shimazaki J. Comparison of deep lamellar keratoplasty and penetrating keratoplasty for lattice and macular corneal dystrophies. Am J Ophthalmol. 2006;142:304-309. doi:10.1016/j.ajo.2006. 03.057

15. Shimazaki J, Shimmura S, Ishioka M, Tsubota K. Randomized clinical trial of deep lamellar keratoplasty vs penetrating keratoplasty. $A m$ $J$ Ophthalmol. 2002;134:159-165. doi:10.1016/S0002-9394(02)01 523-4

16. Cheng J, Qi X, Zhao J, Zhai H, Xie L. Comparison of penetrating keratoplasty and deep lamellar keratoplasty for macular corneal dystrophy and risk factors of recurrence. Ophthalmology. 2013;120 (1):34-39. doi:10.1016/j.ophtha.2012.07.037

17. Reddy JC, Murthy SI, Vaddavalli PK, et al. Clinical outcomes and risk factors for graft failure after deep anterior lamellar keratoplasty and penetrating keratoplasty for macular corneal dystrophy. Cornea. 2015;34(2):171-176. doi:10.1097/ICO.00000 00000000327
18. Sari E, Kubaloglu A, Unal M, et al. Deep anterior lamellar keratoplasty versus penetrating keratoplasty for macular corneal dystrophy: a randomized trial. Am J Ophthalmol. 2013;156(2):267-274.e1. doi:10.1016/j.ajo.2013.03.007

19. Watson SL, Ramsay A, Dart JK, Bunce C, Craig E. Comparison of deep lamellar keratoplasty and penetrating keratoplasty in patients with keratoconus. Ophthalmology. 2004;111(9):1676-1682. doi:10. 1016/j.ophtha.2004.02.010

20. Han DC, Mehta JS, Por YM, Htoon HM, Tan DT. Comparison of outcomes of lamellar keratoplasty and penetrating keratoplasty in keratoconus. Am J Ophthalmol. 2009;148(5):744-751.e1. doi:10. 1016/j.ajo.2009.05.028

21. Meyer HJ. [Prognosis of keratoplasty in hereditary stromal dystrophies]. Klin Monbl Augenheilkd. 1996;208(6):446-449. (German). doi:10.1055/s-2008-1035262

22. Akova YA, Kirkness CM, McCartney AC, Ficker LA, Rice NS, Steele AD. Recurrent macular corneal dystrophy following penetrating keratoplasty. Eye (Lond). 1990;4:698-705. doi:10.1038/eye.1990.98

23. Marcon AS, Cohen EJ, Rapuano CJ, Laibson PR. Recurrence of corneal stromal dystrophies after penetrating keratoplasty. Cornea. 2003;22:19-21. doi:10.1097/00003226-200301000-00005

24. Robin AL, Green WR, Lapsa TP, Hoover RE, Kelley JS. Recurrence of macular corneal dystrophy after lamellar keratoplasty. Am J Ophthalmol. 1977;84:457-461. doi:10.1016/0002-9394(77)90434-2

25. Alzuhairy S, Alkatan HM, Al-Rajhi AA. Prevalence and histopathological characteristics of corneal stromal dystrophies in Saudi Arabia. Middle East Afr J Ophthalmol. 2015;22:179-185. doi:10.4103/09749233.151975

26. Patel AK, Nayak H, Kumar V. Comparative evaluation of big-bubble deep anterior lamellar keratoplasty and penetrating keratoplasty in a case of macular corneal dystrophy. Cornea. 2009;28:583-585. doi:10.1097/ICO.0b013e31818c2c74
Clinical Ophthalmology

\section{Publish your work in this journal}

Clinical Ophthalmology is an international, peer-reviewed journal covering all subspecialties within ophthalmology. Key topics include: Optometry; Visual science; Pharmacology and drug therapy in eye diseases; Basic Sciences; Primary and Secondary eye care; Patient Safety and Quality of Care Improvements. This journal is indexed on PubMed
Dovepress

Central and CAS, and is the official journal of The Society of Clinical Ophthalmology (SCO). The manuscript management system is completely online and includes a very quick and fair peer-review system, which is all easy to use. Visit http://www.dovepress.com/ testimonials.php to read real quotes from published authors. 